\title{
Pulmonary arterial hypertension diagnosed during pregnancy - echocardiography as a tool for management
}

Janez Toplišek ${ }^{1 *}$,
Vojka Gorjup',
Miha Lučovnik',
Tatjana Stopar
Pintarič',
Iva Blajič',
Špela Mušič1,
Barbara Krunić ${ }^{1}$,
Katja Prokšelj',
Špela Tadel Kocjančič',
Anja Čopi Jerman',
Barbara Salobir'

UUniversity Medical Centre Ljubljana, Ljubljana, Slovenia and University of Ljubljana,

Faculty of Medicine, Ljubljana, Slovenia

University Medical Centre Maribor, Maribor, Slovenia

RECEIVED:

February 28, 2019

ACCEPTED:

March 24, 2019

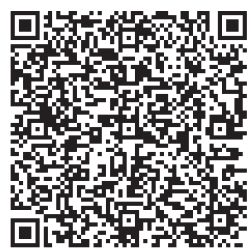

KEYWORDS: pulmonary arterial hypertension, pregnancy, echocardiography, right ventricular function CITATION: Cardiol Croat. 2019;14(3-4):73. | https://doi.org/10.15836/ccar2019.73

*ADDRESS FOR CORRESPONDENCE: Janez Toplišek, Department of Cardiology, University Medical Centre Ljubljana, Zaloška 7, SI-1000 Ljubljana, Slovenia. / Phone: +386-1-522-35-42 / E-mail: jtoplisek@gmail.com ORCID: Janez Toplišek, https://orcid.org/0000-0002-3272-1641

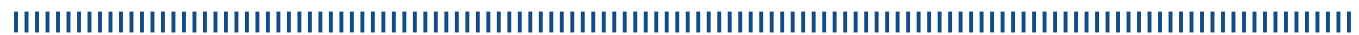

Introduction: Despite advanced therapies for pulmonary arterial hypertension (PAH), maternal mortality in women with PAH and their offspring remains high (30-56\% and 11-28\%) and is especially high during the post-partum period ${ }^{1,2}$.

Case report: 39 -years-old woman was presented in $24^{\text {th }}$ week of pregnancy with moderate dyspnea and cyanosis without peripheral edema. ECG showed right ventricular strain and NT-proBNP was $1300 \mathrm{ng} / \mathrm{L}$. Echocardiogram showed severe precapillary pulmonary hypertension with systolic pulmonary pressure (PAP) $103 \mathrm{mmHg}$, reduced stroke volume (SVI $\left.29 \mathrm{ml} / \mathrm{m}^{2}\right)$, normal cardiac output (CI $2.6 \mathrm{~L} / \mathrm{min} / \mathrm{m}^{2}$ ) and mildly reduced systolic function of the right ventricle (FAC 30\%, PMI TDI 0.8) with normal central venous pressure (CVP) $3 \mathrm{mmHg}$. Right heart catheterization confirmed echocardiographic hemodynamic measurements (mean pulmonary pressure $61 \mathrm{mmHg}$, pulmonary vascular resistance (PVR) 9.4 WU) and the vasoreactivity test was negative. Epoprostenol was initiated, titrated up to $22 \mathrm{ng} / \mathrm{kg} / \mathrm{min}$ and on $30^{\text {th }}$ week planned caesarean section was performed with NO inhalations, noradrenalin and dobutamine. Fortunately, standby supportive therapy - ECMO and high urgency lung transplantation, was not needed. The baby did well. The patient was extubated on the same day and sildenafil was added. The patient was discharged after 4 weeks. After 2 months epoprostenol was switched to treprostinil up to $26 \mathrm{ng} / \mathrm{kg} / \mathrm{min}$ and macitentan was added. NT-proBNP stabilized at $170 \mathrm{ng} / \mathrm{L}$. Echocardiography was performed weekly to monitor CI, CVP and right systolic function indexes. Favorable echocardiographic dynamics after therapy were observed: mean PAP $60 \mathrm{mmHg}$ to 45-50 mmHg, PVR from 10 WU to $7 \mathrm{WU}$, stroke volume normalized and CVP remained normal. However, right ventricular systolic function improved but did not normalize (Table 1).

In conclusion, with complete echocardiographic hemodynamic assessment and thorough clinical assessment high-risk pregnancies in patients with severe PAH can be managed. In addition, FAC, MPI TDI, 3D ejection fraction and RV free strain better assess right ventricular systolic function than TAPSE.
TABLE 1. Echocardiography variables before and after therapy.

\begin{tabular}{lll}
\hline SPAP mmHg & 106 & 64 \\
\hline mPAP mmHg & 64 & 42 \\
\hline PVR (WU) & 10 & 7 \\
\hline RAP mmHg & 3 & 3 \\
\hline SV ml & 51 & 69 \\
\hline SVI ml/m ${ }^{2}$ & 29 & 40 \\
\hline $\mathrm{CO}$ L/min & 4.6 & 4.7 \\
\hline CI L/min/m ${ }^{2}$ & 2.6 & 2.7 \\
\hline RA cm ${ }^{2}$ & 26 & 26 \\
\hline RV TAPSE cm & 1.8 & 2.4 \\
\hline RV FAC \% & 24 & 30 (3D EF 36\%) \\
\hline RV MPI TDI & 0.8 & 0.6 \\
\hline RV free strain \% & -12 & -24 \\
\hline LV Eccentricity index & $2.4 / 3.9$ & $1.5 / 2.1$ \\
\hline Pericardial effusion & minimal & minimal \\
\hline
\end{tabular}

SPAP = systolic pulmonary artery pressure, $\mathrm{mPAP}=$ mean pulmonary artery pressure, $\mathrm{PVR}=$ pulmonary vascular resistance, RAP = right atrial pressure, $\mathrm{SV}=$ stroke volume, $\mathrm{SVI}=$ stroke volu me index, $\mathrm{CO}$ = cardiac output, $\mathrm{Cl}=$ cardiac index, $\mathrm{RA}=$ right atrial area, RV = right ventricle, TAPSE = tricuspid annular plane systolic excursion, $F A C=$ fractional area change, $\mathrm{MPITDI}=$ myocardial performance index, 3D EF = three-dimensional ejection fraction, $\mathrm{RV}$ free strain = right ventricular free wall longitudinal strain.

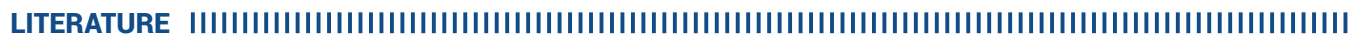

1. Galiè N, Humbert M, Vachiery JL, Gibbs S, Lang I, Torbicki A, et al; ESC Scientific Document Group. 2015 ESC/ERS Guidelines for the diagnosis and treatment of pulmonary hypertension: The Joint Task Force for the Diagnosis and Treatment of Pulmonary Hypertension of the European Society of Cardiology (ESC) and the European Respiratory Society (ERS): Endorsed by: Association for European Paediatric and Congenital Cardiology (AEPC), International Society for Heart and Lung Transplantation (ISHLT). Eur Heart J. 2016 Jan 1;37(1):67-119. https://doi.org/10.1093/eurheartj/ehv317 2. Olsson KM, Channick R. Pregnancy in pulmonary arterial hypertension. Eur Respir Rev. 2016 Dec;25(142):431-437. https://doi.org/10.1183/16000617.0079-2016 